\title{
Modelling the heat dynamics of a residential building unit: Application to Norwegian buildings
}

\author{
D.W.U. Perera C. F. Pfeiffer N.-O Skeie \\ Faculty of Technology, Telemark University College, Postboks 203, N-3901, Porsgrunn, Norway. E-mail: wath- \\ sala.perera@hit.no
}

\begin{abstract}
The paper refers to the development of a continuous time mathematical heating model for a building unit based on the first principles. The model is described in terms of the state space variables, and a lumped parameter approach is used to represent the room air temperature and air density using mass and energy balances. The one-dimensional heat equation in cartesian coordinates and spherical coordinates is discretized in order to describe the thermic characteristics of the layers of the building framework and furniture respectively. The developed model is implemented in a MATLAB environment, and mainly a theoretical approach is used to validate it for a residential building unit. Model is also validated using experimental data for a limited period. Short term simulations are used to test the energy efficiency of the building unit with regard to factors such as the operation of heat sources, ventilation, occupancy patterns of people, weather conditions, features of the building structure and heat recovery. The results are consistent and are obtained considerably fast, implying that the model can be used further in modelling the heating dynamics of complex architectural designs and in control applications.
\end{abstract}

Keywords: Heating model, Heat recovery, Power consumption, Residential building unit, Ventilation

\section{Introduction}

According to the International Energy Agency statistics, both residential and commercial building sectors represent $32 \%$ of the final energy consumption in the world. Heating, cooling and lighting are the primary energy consumers in buildings, and when it comes to northern countries, heating is predominant. Besides, Scandinavian countries experience relatively cold climate conditions which prevail for approximately one third of the year and require more energy demand in heating. The government sectors have introduced policies mainly as regulatory instruments, to reduce the energy demand in the building sector. To improve energy efficiency and to cut down energy consumption, it is essential to be aware of the energy usage patterns, occupant behaviour, operation of appliances, climate conditions, heat transfer characteristics and ventilation requirements. Heating models can be established based on first principles, system identification methods and statistics to assess the energy usage of buildings by combining with the available data. Moreover, a wellbuilt model can be used as a control strategy in energy management systems.

A building unit is a basic unit used to represent the rooms of a building. It is used for modelling purposes and consists of the principal components of a building such as walls, floor, roof, window, door, furniture, heating and ventilation. There are diverse publications related to the simulation of heat dynamics of building units. Most of them use proprietary softwares associated with Computational Fluid Dynamics (CFD) methods as presented in Wang and Wong (2009) and Gendelis and Jakovics (2010). CFD is a robust tool for analyzing indoor air temperature distribution and air flow velocity gradients, but it does not usually provide 
explicit models. For this reason, CFD models cannot be easily integrated with open architectural systems. Mendes et al. (2003), Andersen et al. (2000), Kazanavicius et al. (2006), Lee et al. (2011) and Desta et al. (2005) have developed good dynamic mathematical models for characterizing the thermal performance of building units, yet most of them lack of the modelling of the heat loss associated with ventilation. Furthermore, none of the referred articles have proposed the modelling of the thermal mass of household goods such as furniture. In the model introduced in Mendes et al. (2003), a set of ordinary differential equations describe four states, which are the temperature of air, walls and an electric heater together with the latent heat release by water vapour present in the building. The work performed by Andersen et al. (2000) is about the modelling of air temperature and floor temperature for a single storeyed non-ventilated two zone building unit. Simultaneously, the thermal energy released to the interior by solar radiation is presented in detail. The building thermal storage effect is formulated as a model in Kazanavicius et al. (2006) with consideration of weather data, mass flow of the radiator and indoor temperature. The dynamic heating model presented in Lee et al. (2011) is more or less equal to work done by Mendes et al. (2003). They have also built a statistical model that contributes to the understanding of the energy usage patterns. The heat transfer phenomenon inside a ventilated air space is described using the data based mechanistic model by Desta et al. (2005). Their approach mainly gives an account of the heat loss by ventilation, heat transfer through the building envelopes and inside heat generation.

The intention of this task is to highlight an in-depth dynamic heating model to integrate it with an open architectural energy control system. It makes up for most of the deficiencies present in the published explicit building heating models. A well mixed zone theory is used to model the air temperature and air density within the building unit. It is also merged with the thermal masses of walls, floor, roof and household goods. The ventilation plays a significant role in determining the total energy loss. The primary model of the building unit can be used with relevant adjustments to develop models for complex architectures. This will be undertaken in the future work.

The rest of the paper presents the details about Norwegian buildings and regulations, the heating model development approach, the test building unit and evaluation of the results obtained by the model simulations. After that, the model is validated for the experimental data considering a residential building in Norway. Finally, closing conclusions about the work and future research areas are presented.

\section{Buildings in Norway}

In Norway, the thermal comfort of the residents is highly dependent on the outdoor freezing temperatures which dominate from late autumn to early spring. According to Bergesen et al. (2013), 66\% of the total energy consumption of residential buildings occurs in the space heating sector of Norwegian residential buildings. To maintain the indoor thermal comfort and to sustain an acceptable energy economy, the design of buildings with precise heating strategies is important. The principal Norwegian normative document which presents the building technical regulations is the "Norwegian Building Code". TEK10 is the recent issue (2010) of these perspective requirements TEK (2010), and it recommends the values of significant parameters, which pertain to better energy economy and thermal comfort.

The use of wood as a construction material in Norwegian houses is widely known as it can withstand changing weather conditions. Compared to brick houses, wooden houses have a low thermal mass (the ability of a material to store heat, and is a function of specific heat capacity and density of the material) which contributes to a drop in heating demands in cold climates. Usually, the walls, floor and roof are assembled with several layers of different materials. For example, outer walls consist of layers of wood panelling, vapour barrier, insulation, wind barrier and ventilated cladding from the inside surface of the wall to the outside respectively. The presence of floor and roof insulations concurrently enhance the thermal efficiency of Norwegian buildings.

\subsection{Building regulations for Norway}

In accordance with TEK10, the maximum overall heat transfer coefficient, $\mathrm{U}\left(\mathrm{Wm} \mathrm{m}^{-2} K^{-1}\right)$ for the outer walls, roof, ground floor and windows/doors should be kept at values equal to or less than $0.18,0.13,0.15$ and 1.2 respectively. Air exchange in closed buildings is one of the fundamental requirements for achieving thermal comfort and the health of occupants. Total air exchange is twofold; infiltration and ventilation. Fresh air flow rate at a minimum of $1.2 \mathrm{~m}^{3} / \mathrm{h}$ per $1 \mathrm{~m}^{2}$ of floor space when the housing unit is in use, and 0.7 $\mathrm{m}^{3} / \mathrm{h}$ per $1 \mathrm{~m}^{2}$ of floor space when not in use are recommended. Especially, bedrooms should have a fresh air flow at a minimum of $26 \mathrm{~m}^{3} / \mathrm{h}$ for each bed when in use. Inadequate air can give rise to health problems and excessive air is an energy waste. To minimize the 
wastage, window and door areas should be less than or equal to $20 \%$ of the floor area in the heated space.

Minimizing the energy losses, incorporated with the appointed fresh air flow rates, is not easily approachable without heat recovery systems. Therefore, the installation of heat recovery systems is suggested for residential buildings, and their annual average energy efficiency should be above or equal to $70 \%$.

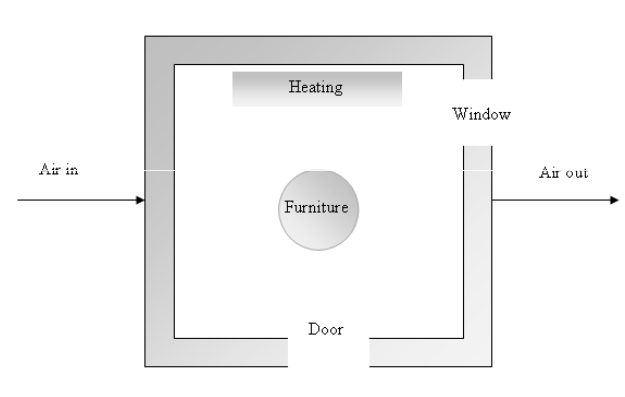

Figure 1: Sketch of a conventional building unit

\subsection{Mechanistic model formulation}

In this section, a mechanistic dynamic heating model is formulated for the building unit presented in Figure 1 , which is considered as a control volume. The formulated mathematical model is based on mass and energy balances and the equations (1) to (23) describe the complete model. The subscripts b, w, f, $r$ and fur denote building unit, walls, floor, roof and furniture respectively. The nomenclature is presented in Table 6 .

$$
\begin{gathered}
\frac{d \rho_{b}}{d t}=\frac{\dot{V}_{\text {in }} \rho_{\text {in }}-\dot{V}_{\text {out }} \rho_{b}}{V_{b}} \\
\frac{d E_{b}}{d t}=\dot{E}_{\text {in }}-\dot{E}_{\text {out }}+\dot{Q}+\dot{W} \\
E_{b}=U_{b}^{E}=H_{b}-P_{b} V_{b} \\
\frac{d T_{b}}{d t}=\frac{\dot{V}_{\text {in }} \rho_{\text {in }} h_{\text {in }}-\dot{V}_{\text {out }} \rho_{b} h_{\text {out }}+\dot{Q}_{\text {in }}}{V_{b} \rho_{b}\left(c_{p, b}-\frac{R}{M_{b}}\right)}-\frac{T_{b}}{\rho_{b}} \frac{d \rho_{b}}{d t} \\
\dot{Q}_{\text {Supply }}=(1) \\
\dot{Q}_{\text {Heater }}+\dot{Q}_{\text {People }}+\dot{Q}_{\text {Appliances }}+\dot{Q}_{\text {Solar }}
\end{gathered}
$$

$$
\begin{gathered}
\frac{d T_{i, w}}{d t}=\alpha_{i, w} \frac{T_{i+1, w}^{s}-2 T_{i, w}+T_{i, w}^{s}}{l_{i, w}^{2}} \\
h_{b, w}\left(T_{b}-T_{i, w}^{s}\right)=\frac{-K_{1, w}}{2 l_{1, w}}\left(T_{2, w}^{s}-T_{1, w}^{s}\right) \\
\frac{-K_{i, w} A_{i+1, w}}{2 l_{i, w}}\left(T_{i+1, w}^{s}-T_{i, w}^{s}\right)=h_{\infty, w} A_{i+1, w} \\
+\sigma \epsilon_{i+1, w}\left(T_{i+1, w}^{s}-T_{\infty}^{4}\right) \\
\frac{d T_{i, f}}{d t}=\alpha_{i, f} \frac{T_{i+1, f}^{s}-2 T_{i, f}+T_{i, f}^{s}}{l_{i, f}^{2}} \frac{q_{i, f}}{\rho_{i, f} c_{p_{i, f}}} \\
h_{b, f}\left(T_{b}-T_{i, f}^{s}\right)=\frac{-K_{1, f}}{2 l_{1, f}}\left(T_{2, f}^{s}-T_{1, f}^{s}\right) \\
\frac{d T_{i, r}}{d t}=\alpha_{i, r} \frac{T_{i+1, r}^{s}-2 T_{i, r}+T_{i, r}^{s}}{l_{i, r}^{2}} \\
\left.h_{b, r}-T_{i, r}^{s}\right)=\frac{-K_{1, r}}{2 l_{1, r}}\left(T_{2, r}^{s}-T_{1, r}^{s}\right)
\end{gathered}
$$$$
\frac{-K_{i, w} A_{i+1, w}}{2 l_{i, w}}\left(T_{i+1, w}^{s}-T_{i, w}^{s}\right)=h_{\infty, w} A_{i+1, w}\left(T_{i+1, w}^{s}-T_{\infty}\right)
$$

$$
\begin{gathered}
\frac{-K_{i, r} A_{i+1, r}}{2 l_{i, r}}\left(T_{i+1, r}^{s}-T_{i, r}^{s}\right)=h_{\infty, r} A_{i+1, r}\left(T_{i+1, r}^{s}-T_{\infty}\right) \\
+\sigma \epsilon_{i+1, r}\left(T_{i+1, r}^{s}{ }^{4}-T_{\infty}^{4}\right)
\end{gathered}
$$

$$
\begin{aligned}
\frac{d T_{i, f u r}}{d t}= & \alpha_{i, f u r}\left(\frac{T_{i+1, f u r}^{s}-2 T_{i, f u r}+T_{i, f u r}^{s}}{\delta r_{i, f u r}^{2}}\right) \\
& +\alpha_{i, f u r}\left(\frac{1}{r} \frac{T_{i+1, f u r}^{s}-T_{i, f u r}^{s}}{\delta r_{i, f u r}}\right)
\end{aligned}
$$

$$
h_{b, f u r}\left(T_{b}-T_{i, f u r}^{s}\right)=\frac{-K_{1, f u r}}{2 l_{1, f u r}}\left(T_{2, f u r}^{s}-T_{1, f u r}^{s}\right)
$$

$$
\dot{Q}_{\text {window }}=U_{\text {window }} A_{\text {window }}\left(T_{b}-T_{\infty}\right)
$$

$$
\dot{Q}_{\text {door }}=U_{\text {door }} A_{\text {door }}\left(T_{b}-T_{\infty}\right)
$$

$$
\dot{Q}_{\text {walls }}=U_{\text {walls }} A_{\text {walls }}\left(T_{b}-T_{\infty}\right)
$$




$$
\begin{gathered}
\dot{Q}_{\text {floor }}=h_{b, \text { fur }} A_{\text {fur }}\left(T_{b}-T_{\text {centre }}\right) \\
\dot{Q}_{\text {roof }}=U_{\text {roof }} A_{\text {roof }}\left(T_{b}-T_{\infty}\right) \\
\dot{Q}_{\text {fur }}=h_{\text {fur }} A_{\text {floor }}\left(T_{b}-T_{\infty}\right) \\
T_{\text {in }}=\frac{\eta \dot{V}_{\text {out }} \rho_{b} c_{p, b}\left(T_{b}-T_{\infty}\right)}{\dot{V}_{\text {in }} \rho_{\text {in }} c_{p, \text { in }}}+T_{\infty}
\end{gathered}
$$

Ventilation plays a leading role in the convective mode of heat transfer in buildings. The application of mass balance to the air flow is, therefore, vital in the modelling of ventilated spaces. The representative mass balance equation under completely mixed conditions for a building unit of volume of $V_{b}$ can be written as given in eq.(1). Subscript "b" denotes the building unit of interest. Outdoor relative humidity $(\mathrm{RH})$ readings and the ideal gas law are used to determine the density of air running into $\left(\rho_{i n}\right)$ the ventilated hygrothermal building unit. The discharge air density is equal to the air density inside the unit $\left(\rho_{b}\right)$ because of the approximation of completely mixed conditions. $\dot{V}_{\text {in }}$ and $\dot{V}_{\text {out }}$ are the terms specifying the airflow rates into and out of the building envelope owing to both mechanical ventilation and infiltration. As the specifications of mechanical ventilators are not imminent, those terms are approximated by using the ventilation controls provided in TEK10 throughout the study. The developed simple mass balance statement gives quite a number of important facts associated with building energy consumption which have not been utilized in most of the available publications.

The energy balance equation for the control volume of interest, with six surfaces, is given in eq.(5). It is developed by using the general energy balance equation (eq.(2)) with several simplifications, including eq.(3) and eq.(4). $E_{b}$ is the total energy of the control volume, which consists of kinetic, potential and internal energies. Air flow velocity inside the single zone building unit is very low and insignificant. Hence kinetic energy is not taken into consideration. The potential energy of the system is also of minor importance. Nothing but the internal energy $\left(U_{b}^{E}\right)$ term is taken into account. $H_{b}$ and $P_{b}$ denote the enthalpy and pressure inside the building unit respectively. $\mathrm{W}$ is a combination of pressure work, expansion work and friction work. As the volume of the room is fixed, expansion work is zero and friction work can be approximated to zero because air is the fluid of interest. Pressure work is the only term that signifies the energy transfer by work in this model. The application of eq.(3), eq.(4), ideal gas law, molar mass, specific enthalpies and the relation $\mathrm{d} H_{b}=\mathrm{d}\left(m_{b} c_{p, b} T_{b}\right)$ to eq.(2), finalizes the energy balance for the building unit.

The term $\left(\dot{V}_{\text {in }} \rho_{\text {in }} h_{\text {in }}-\dot{V}_{\text {out }} \rho_{\text {out }} h_{\text {out }}\right)$ addresses the ventilation heat losses. $\dot{Q}$ is the total heat flow of the room owing to matters other than ventilation, and by definition it is equal to $\dot{Q}=\dot{Q}_{\text {Supply }}-\dot{Q}_{\text {Loss }}$. There are several routes of heat addition into a residential building. The foremost heat regulator is the electric heater, and within this work it is in operation to control and ensure the indoor thermal comfort. Internal energy gains from people and electrical devices also tend to increase the indoor temperature. The aggregation of solar irradiation together with these factors summarize the total heat supply to the building unit as in eq.(6). The surrounding walls, floor, roof together with the window and door are the main items that allow the flow of heat outside the system of interest. Moreover, furniture may absorb thermal energy from the hot air, acting as a heat sink. The thermal properties of these structures are described by partial differential equations owing to the clear variation of the temperature profile within them.

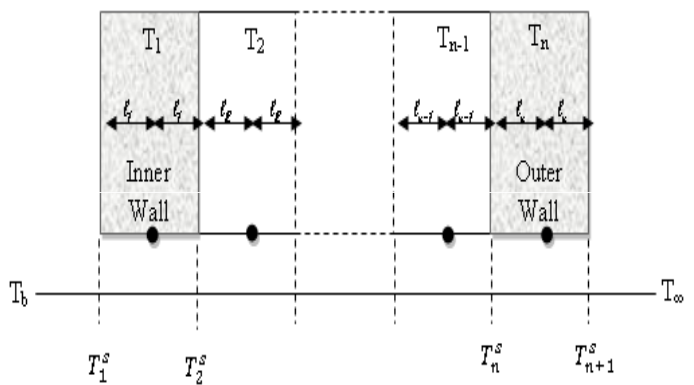

Figure 2: Distribution of temperature in a longitudinal section of a wall

The building framework consists of layers of different materials. Wooden panels are a preferred material when constructing the walls of most of Norwegian residential houses. The volume between the inner and outer wooden coverings is filled up with insulation materials to overcome heat losses (Figure 2). Mendes et al. (2003) and Lee et al. (2011) have proposed ordinary differential equations which describe the heat dynamics of the different layers of the wall. In this work, a transient heat equation (eq.(24)) is used as the energy balance for the distinct layers of the walls, and $\alpha$ is the effective thermal diffusivity of the body given by $\frac{K}{\rho c_{p}}$, where $\mathrm{K}$ is the thermal conductivity, $\rho$ is density and 
$c_{p}$ is the specific heat capacity.

$$
\frac{\partial T}{\partial t}-\alpha \nabla^{2} T-\frac{\dot{q}}{\rho C_{p}}=0,
$$

Heat is transferred through the wall from the inside of the building to the outside. Therefore, it is acceptable to have one-dimensional heat transfer equations deduced from eq.(24). To simplify the problem, extracted equations are transformed to ordinary differential equations using the finite difference method. It is assumed that the temperature throughout each layer of the wall is uniform. Further, the surface temperatures are approximated as the mean temperature of the two consecutive layers. $\dot{q}$ is zero being equal to no heat generation within the wall. eq.(7) is the energy balance for each $i^{\text {th }}$ layer of wall. Boundary conditions for internal and external layers of the wall are presented by eq.(8) and eq.(9).

The same concept can be used to derive the appropriate heat transfer equations for the floor and roof of the building unit. In addition, the heat equation of the floor consists of a source term indicating the presence of a floor heater. eq.(10) and eq.(11) describe the thermic processes of floor and eq.(12), eq.(13) and eq.(14) determine the thermal characteristics of a flat roof, where the subscripts "f" and "r" represent the floor and roof respectively.

The modelling of household furniture is vital because it acts as either a heat sink or a heat source depending on the surrounding temperature. A portion of energy supplied by the heater is stored in the furniture as thermal energy. This process happens until its body temperature is in equilibrium with the indoor air temperature. The indicated process will increase the time required for heating the room to a desirable level. Concurrently, it takes a long time to cool down a building because the process of heat release from furniture is slow. Heat capacity and thermal conductivity of the material of construction determine the rate of the heat absorption or release. To simplify the modelling approach of furniture, it is assumed that it behaves like a sphere with the same mass and equivalent average thermal diffusivity that can be found experimentally. The heat equation in spherical coordinates is given by;

$$
r^{2} \frac{\partial T}{\partial t}-\alpha \frac{\partial}{\partial r}\left(r^{2} \frac{\partial T}{\partial r}\right)-r^{2} \frac{\dot{q}}{\rho C_{p}}=0
$$

After discretization of eq.(25) using the finite difference method, eq.(15) is obtained for each spherical layer i. As there is no heat generation, the term $(\dot{q})$ can be eliminated. eq.(16) presents the boundary condition for the outer layer of the sphere.

Except for the heat losses via walls, floor, roof and furniture (eq.(19), eq.(20), eq.(21), eq.(22)), there are two more heat losses that need to be addressed. They are the losses via windows and doors, which are described by eq.(17) and eq.(18).

With an integrated ventilation heat recovery system, air inflow temperature will be higher compared to the outside temperature. It is possible to estimate this temperature using an energy efficiency $\eta$, and with the assumption of equal densities and specific heat capacities in the two counter current air flow streams. eq. (23) is for computing the air inflow temperature after the economizer. With this installation, the thermal properties of inlet air should be calculated with regard to this new temperature $\left(T_{i n}\right)$.

With all these equations presented, the dynamic heating model is ready to be used as described in the consecutive sections.

\section{The test building unit}

Figure 3 illustrates the building unit with an outer dimension of $3.65 \mathrm{~m} \times 4 \mathrm{~m} \times 3.3 \mathrm{~m}(\mathrm{~L} \times \mathrm{W} \times \mathrm{H})$, which is chosen for modelling. It consists of one window with an area of $1 \mathrm{~m} \times 1.2 \mathrm{~m}(\mathrm{~W} \times \mathrm{H})$ and one door sized $0.75 \mathrm{~m} \times 2.1 \mathrm{~m}(\mathrm{~W} \times \mathrm{H})$. The walls, roof and floor of the unit have a thickness of $0.2 \mathrm{~m}, 0.24 \mathrm{~m}$ and $0.17 \mathrm{~m}$ respectively.

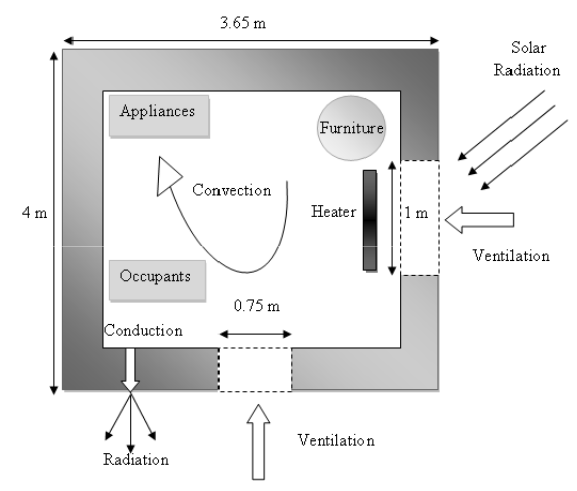

Figure 3: Dimensions and elements of the building unit

The primary heat supply to the zone is by an On/Off type electrical heater with a full capacity of $1 \mathrm{~kW}$ $\left(\dot{Q}_{\text {Heater }}\right)$. Cooling down any building to sub-zero temperatures is not recommended since water sources can freeze and damage pipes throughout the house. Nearly all of the controllable commercial heating systems in Norway use $15^{\circ} \mathrm{C}$ as the energy saving set point, which is the suggested temperature for the energy saving periods when the building is not in use. While in use, $20^{\circ} \mathrm{C}$ is the comfortable set point temperature. These two temperatures are the fixed points in this study, 
and it is necessary to keep to these requirements by turning the heater on and off. The controller operates with a dead zone defined by $\pm 1^{0} \mathrm{C}$ around the set point value. The determination of the usage pattern of the building is important for better control of the heater. Moreover, there are four energy saving events specified in this task, and they are, "Wake, Leave, Return and Sleep". With these four events, a period of one day is split up into 4 sections so that during 8:00 to 16:00 the room is not occupied and during 23:00 to 6:30 the occupants are asleep. The building is occupied for the rest of the time slots.

Besides the heat supply from the electrical heater, other electrical appliances such as a refrigerator, personal computer, light bulb and water heater are in operation, emitting a fraction of internal heat production to the surroundings. These internal gains also tend to increase the indoor temperature by a significant amount. An incandescent light bulb more or less converts not more than $10 \%$ of the total energy into light energy, and the rest is dissipated as thermal energy. All the electrical appliances are assumed to contribute to heating the building unit by $150 \mathrm{~W}$.

According to Havenith et al. (2002), the heat released by an average-sized person through metabolic activities is approximately $58.2 \mathrm{Wm}^{-2}$. Therefore, it is possible to approximate a heat release of $80 \mathrm{~W}$ when the building unit is occupied by one person with a body surface area of $1.4 m^{2}$.

Glass windows let the solar irradiation pass through their transparent surfaces. A fraction of incident solar radiation is transmitted into the inside space, raising the temperature of both air and possibly the floor or furniture when these are exposed to direct sunlight. The solar heat gain coefficient (SHGC) defines the portion of solar energy allowed to pass through the surface. Most of the available windows have a SHGC of 0-60\% Harley (2002). Annual average solar irradiation in Norway is around $100 \mathrm{Wm}^{-2}$ Olseth and Skartveit (1986), and during the cold winter periods, it can go below the average value. In the simulations, the period where sunshine is available is approximated as 10:00 to 14:00 during the winter time.

The mechanical ventilation system present in the building unit enables the control of the air flow rate as directed by the Norwegian regulations. Besides, equal volumetric inflow and outflow rates are used in the validations. The approach of equal air flow rates (but different mass flow rates owing to density difference) is used because of the unavailability of the specifications of mechanical ventilation systems related to this theoretical work.

The fraction of thermal losses from the building unit is by means of heat transfer through walls, roof, floor, door and window. Overall heat transfer coefficients are restricted to be at the upper limit as recommended by TEK10. Warm outer surfaces of the walls and roof emit radiative heat to the environment, but this phenomenon is small in cold Norwegian climates.

The furniture inside the building unit acts as either a heat sink or a heat source depending on the current indoor temperature, as described in the previous section. Principally, the furniture is assumed to be made of wood. Moreover, furniture will fill up a volume of $1 m^{3}$.

Outside conditions give a noticeable effect on the indoor thermal qualities. It is necessary to have outside weather data (Temperature and Relative Humidity) which can be applied in the model. This information is extracted from the "Norwegian Meteorological Institute" web site (yr.no) for the month of February, 2012 in Oslo (Blindern) and averaged to obtain a profile of hourly mean values fitted to a 24-hours period. The average ground temperature is approximated to be $5^{0} \mathrm{C}$ higher than the outdoor temperature, and knowledge about the ground temperature is a requirement in determining the heat transfer via the floor of the building.

Thermal parameters associated with the building enclosure and furniture are given in the Table 1 . The values are estimated for typical Norwegian buildings from Frostrup (1999). The values of heat transfer coefficients are chosen based on TEK10 standards and they are presented in Table 2. Thermal conductivities, thermal diffusivities and half thicknesses of each layer of walls, floor and roof are presented for $i^{\text {th }}$ layer. Overall heat transfer coefficients of walls, floor and roof can be estimated from the given thermal conductivities and heat transfer coefficients. Densities and specific heat capacities of each layer of the floor are also shown.

\section{Results and discussion}

Within this section, the performance of the developed model is analyzed by 7 different cases. Each of them is implemented in a MATLAB environment and solved using ode15s after specifying initial conditions for all the state variables. Table 3 summarizes the variants of the inputs and physical parameter settings of the building unit for each case. Performance analysis of the model is mainly a theoretical investigation. In the section 5 , simple experimental validation is done with a limited amount of experimental data.

Case 4 is composed of three distinctive approaches depending on the characteristics of furniture. In case 6 , the size of the building unit is doubled by increasing the floor area. Further, case 7 is different from the others owing to the combination of two separate building 
Table 1: Parameters applicable to walls, floor, roof and furniture

\begin{tabular}{|c|c|c|c|c|c|}
\hline \multicolumn{2}{|c|}{ Parameter } & \multirow{2}{*}{$\begin{array}{c}\text { Layer 1 } \\
\text { (Inside) }\end{array}$} & \multirow{2}{*}{$\begin{array}{c}\text { Layer } 2 \\
0.038\end{array}$} & \multirow{2}{*}{$\begin{array}{c}\text { Layer } 3 \\
0.026\end{array}$} & \multirow{2}{*}{$\begin{array}{c}\text { Layer } 4 \\
0.14\end{array}$} \\
\hline$K_{i, w}$ & {$[\mathrm{~W} /(\mathrm{mK})]$} & & & & \\
\hline$K_{i, r}$ & {$[\mathrm{~W} /(\mathrm{mK})]$} & 0.14 & 0.038 & 0.12 & 0.027 \\
\hline$K_{i, f}$ & {$[\mathrm{~W} /(\mathrm{mK})]$} & 0.027 & 0.14 & 0.038 & \\
\hline$K_{f u r}$ & {$[\mathrm{~W} /(\mathrm{mK})]$} & 2 & & & \\
\hline$\alpha_{i, w}$ & {$\left[\mathrm{~m}^{2} / \mathrm{s}\right]$} & $1.7 \times 10^{-7}$ & $1.4 \times 10^{-6}$ & $2.25 \times 10^{-2}$ & $1.7 \times 10^{-7}$ \\
\hline$\alpha_{i, r}$ & {$\left[\mathrm{~m}^{2} / \mathrm{s}\right]$} & $1.7 \times 10^{-7}$ & $1.4 \times 10^{-6}$ & $1.8 \times 10^{-7}$ & $4 \times 10^{-7}$ \\
\hline$\alpha_{i, f}$ & {$\left[\mathrm{~m}^{2} / \mathrm{s}\right]$} & $4 \times 10^{-7}$ & $1.7 \times 10^{-7}$ & $1.4 \times 10^{-6}$ & \\
\hline$\alpha_{f u r}$ & {$\left[m^{2} / \mathrm{s}\right]$} & $1.8 \times 10^{-7}$ & & & \\
\hline$l_{i, w}$ & {$[\mathrm{~m}]$} & $6 \times 10^{-3}$ & $75 \times 10^{-3}$ & $8.5 \times 10^{-3}$ & $8.5 \times 10^{-3}$ \\
\hline$l_{i, r}$ & {$[\mathrm{~m}]$} & $6 \times 10^{-3}$ & $100 \times 10^{-3}$ & $11 \times 10^{-3}$ & $6.5 \times 10^{-4}$ \\
\hline$l_{i, f}$ & {$[\mathrm{~m}]$} & $1 \times 10^{-3}$ & $9 \times 10^{-3}$ & $75 \times 10^{-3}$ & \\
\hline$\rho_{i, f}$ & {$\left[\mathrm{~kg} /\left(m^{3}\right)\right]$} & 55 & 615 & 32 & \\
\hline$c_{p, f}$ & {$[\mathrm{~J} /(\mathrm{kgK})]$} & 1210 & 1317 & 835 & \\
\hline
\end{tabular}

Table 2: Heat transfer coefficients $\left[\mathrm{W} /\left(\mathrm{m}^{2} \mathrm{~K}\right)\right]$

\begin{tabular}{lc}
\hline Parameter & Value \\
\hline$h_{b, w}$ & 2 \\
$h_{\alpha, w}$ & 1 \\
$h_{b, r}$ & 2 \\
$h_{\alpha, r}$ & 1 \\
$h_{b, f}$ & 2 \\
$h_{b, \text { fur }}$ & 2 \\
$U_{\text {window }}$ & 1.2 \\
$U_{\text {door }}$ & 1.2 \\
\hline
\end{tabular}

Table 3: Properties of variants in simulated scenarios

\begin{tabular}{lccccccccc}
\hline Property & C1 & C2 & C3 & C4a & C4b & C4c & C5 & C6 & C7 \\
\hline Heat supply, kW & $1-0$ & 1 & 1 & 1 & 1 & 1 & 1 & 1 & 1 \\
Heating control & No & On/Off & On/Off & On/Off & On/Off & On/Off & On/Off & On/Off & On/Off \\
Air flow, $\left.m^{3} / m^{2} . \mathrm{h}\right)$ & 0.7 & TEK10 & 0 & TEK10 & TEK10 & TEK10 & TEK10 & TEK10 & TEK10 \\
Outside T, ${ }^{0} \mathrm{C}$ & -2.2 & Varying & Varying & Varying & Varying & Varying & Varying & Varying Varying \\
Outside RH & 0.77 & Varying & Varying & Varying & Varying & Varying & Varying & Varying Varying \\
Occupancy & No & Yes & Yes & Yes & Yes & Yes & Yes & Yes & Yes \\
Insolation, W $/ m^{2}$ & 0 & 100 & 100 & 100 & 100 & 100 & 100 & 100 & 100 \\
Appliances, W & 0 & 150 & 150 & 150 & 150 & 150 & 150 & 150 & 150 \\
Furniture vol., $m^{3}$ & 1 & 1 & 1 & 2 & 1 & 0 & 1 & 1 & 1 \\
Furniture material & Wood & Wood & Wood & Wood & Steel & - & Wood & Wood & Wood \\
Heat recovery & No & No & No & No & No & No & Yes & No & No \\
Area, $m^{2}$ & $3.65 \times 4$ & $3.65 \times 4$ & $3.65 \times 4$ & $3.65 \times 4$ & $3.65 \times 4$ & $3.65 \times 4$ & $3.65 \times 4$ & $7.3 \times 8$ & $3.65 \times 4$ \\
No of units & 1 & 1 & 1 & 1 & 1 & 1 & 1 & 1 & 2 \\
\hline
\end{tabular}


units. The properties listed for this case only concern the main building unit, and details about the second unit are given underneath.

\subsection{Case 1}

The single zone building unit with one door and one window presented in Figure 3 is used in this evaluation study. Simulation is carried out for a constant heat supply of $1 \mathrm{~kW}$ for 50 hours and no supply for the next 50 hours, such that there is no control of the temperature inside the unit. The ultimate goal of this simulation is to recognize how fast the indoor temperature can increase when heating and how quickly the room cools down. Therefore, none of the other heat supplies are in operation. Further, to observe the precise behaviour of the indoor temperature, it is important to adhere to uniform outside temperature and $\mathrm{RH}$ profiles. While the initial temperature of the air and other internal building elements are at $20^{\circ} \mathrm{C}$, Figure 4 shows the temperature profiles of indoor air, the internal temperature of wall, roof, floor and the external surface temperature of the furniture. Internal surface temperatures of the roof and floor show equal temperature fluctuations as can be seen from the figure.

Even after 50 hrs of heating and cooling with constant external disturbances, there is a non-zero steady state error present in the room air temperature profile. The indoor air temperature gains $32.5^{0} \mathrm{C}$ after 50 hours of heating. At the $50^{\text {th }}$ hour, the heater is turned off, and then the temperature starts to decline. After 100 hours, it reaches $1^{0} \mathrm{C}$, showing a $51.5^{0} \mathrm{C}$ reduction. Hence, cooling of the building is much faster than heating. This result is acceptable because with the air circulation, heating the building is much harder than cooling it. It is also noted that heating of the other solid structures is slower than heating the air, which makes sense.

\subsection{Case 2}

In this case, the heat dynamics of the building unit is examined with a heater associated with an On/Off controller. When the building is in use, the set temperature is $20^{\circ} \mathrm{C}$ in order to avoid the discomfort of the occupants. During the rest of the time, the temperature can be reduced to $15^{0} \mathrm{C}$ by controlling the heater at appropriate instances. The outdoor temperature and $\mathrm{RH}$ profiles are used in this simulation and are not fixed as in case 1 . There is a circulating air flow into the building unit, and it has a value in accordance with the TEK10 regulation requirements. All of the other heat supplies, in addition to the heater, influence the thermal behavior of the building unit. Figure 5 gives

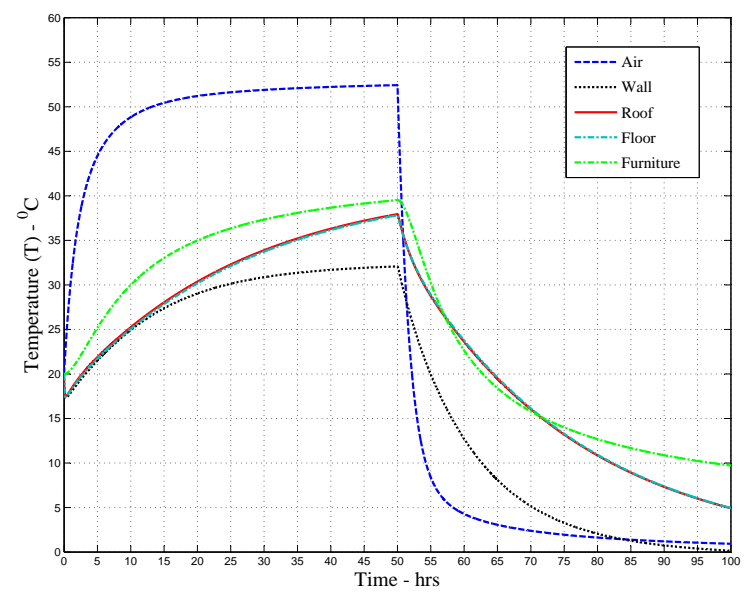

Figure 4: Temperature variations of air and other elements internal to the building unit

the particulars regarding the indoor temperature and air density variation.

The control system uses around 0.2 hrs for heating and $1 \mathrm{hr}$ for cooling the room in between admissible set temperatures. The required time for heating depends on the available heat sources within each period. A significant fraction of electrical energy can be saved by means of incident solar radiation which is available only during the day time from 10:00 to 14:00. For the other periods, the operation of the heater dominates and, therefore, the temperature fluctuates highly around the expected value. Throughout the day, electrical appliances are dissipating energy, and while the building is in use, substantial heat gain from the humans is expected. The existence of equal air inflow and outflow rates limits the density fluctuations.

\subsection{Case 3}

In order to assess the effect of ventilation on the performance of the electrical power consumption, an analysis is conducted assuming that the building unit is hermetically sealed. Figure 6 shows the relevant variations of temperature to this examination.

As there is no ventilation, air density is uniform throughout the period. Cooling down the building unit is slow mainly due to the unavailability of airing. Heat dissipated by the electrical appliances, human body and heat release from the furniture put the heater in cessation up to 6:00. Starting from 8:00 the temperature in the room declines once again until it reaches $15^{0} \mathrm{C}$. This reduction is faster compared to the previous because the outside temperature has its lowest values 


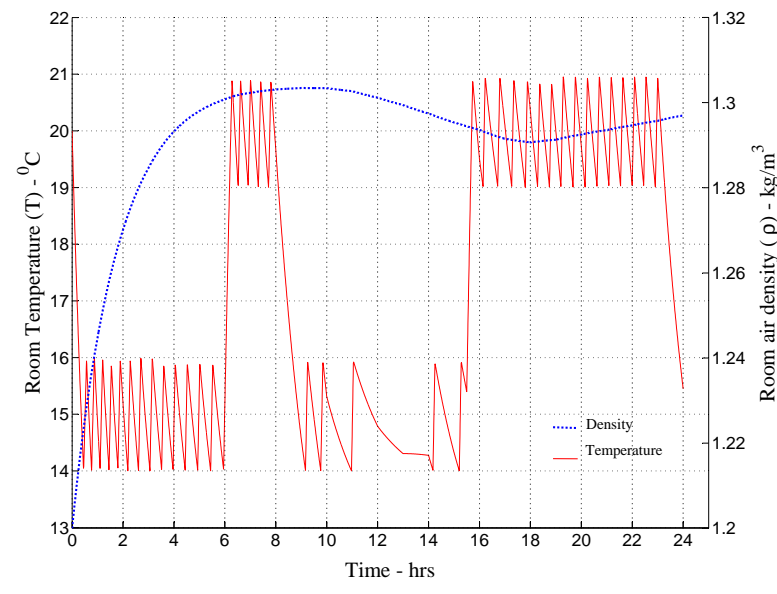

Figure 5: Temperature and density variations inside the building unit with On/Off control

during this period, and no heat radiation is available from the occupants. As mentioned in the previous case, solar irradiation lessens the need to have the heater on during the day, which is true for this case too.

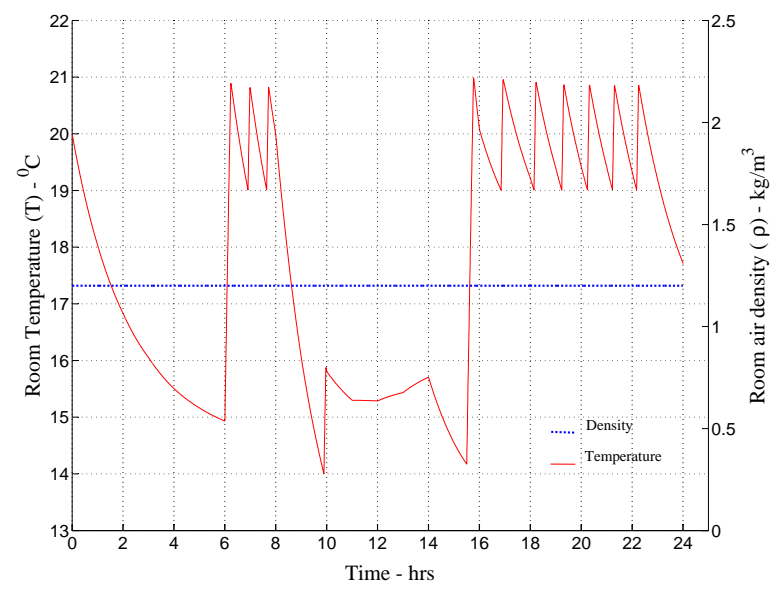

Figure 6: Temperature variation inside the hermetically sealed building unit with On/Off control

\subsection{Case 4}

A description of the heat dynamics of furniture is one of the main feature of the developed building heating model. The simulations performed in the three latter cases are equipped with wooden furniture with a volume of $1 \mathrm{~m}^{3}$ in each. This case consists of three po- tential occurrences: increase the total volume of the wooden furniture to $2 \mathrm{~m}^{3}$; change the material of construction to steel with $1 \mathrm{~m}^{3}$ volume and no presence of furniture. Results from case 2 are used as the base case scenario in analyzing these alternatives. Figure 7 shows the temperature variations in each layer of the spherical furniture and layer 1 is exposed to the surroundings.

The specific heat capacity of wood is more than twice as high compared to steel, but the density of steel is almost ten times greater than wood which contributes to increase the thermal mass per unit volume of steel. From the data it is found that the thermal mass of wood is approximately one tenth compared to a similar volume of steel. In situations where low levels of thermal mass exists, such as in wooden furniture, rapid heating and cooling will occur. Materials having high thermal mass respond to heating and cooling slowly and also reduce the necessity for heating and cooling. This effect is clearly illustrated in Figure 7; where the external surface of the wood furniture behaves in parallel with the room temperature. The thermal storage capacity of steel is also high due to its thermal mass and, hence it can improve the thermal comfort of the building during low temperature conditions. The discharge of stored energy causes the internal temperature of the steel furniture to fall.

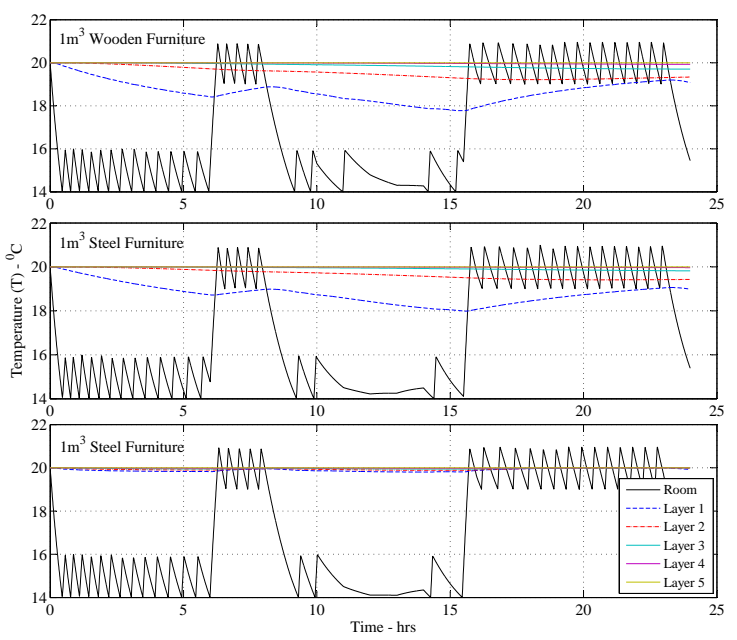

Figure 7: Temperature variations across the spherical furniture element and room temperature variations

The free electrons present in steel can conduct the heat faster towards the center of the structure compared to wood. All the energy transferred to the steel surface by convection is then transported quickly to the middle of the sphere owing to low specific heat capac- 
ity and high thermal conductivity. Heat absorbed by the surface of the wood is not capable of moving to the middle with the same rate. This constitutes the dominant temperature gradients in the wooden furniture.

When the volume of the wooden furniture increases, it requires additional time to transfer heat to the core. Increasing the volume of a sphere by two, does not increase the radius significantly. Therefore, it is not possible to see clear temperature variations in the layers of the larger sphere compared to the smaller one. However, it is deemed to take longer to raise the temperature with $2 \mathrm{~m}^{3}$ volume of furniture than with $1 \mathrm{~m}^{3}$ volume.

Furniture will release part of the absorbed thermal energy in a colder building unit and vice versa. Each analysis with furniture shows a net heat release which is roughly equal to $0.5,1.1$ and $1.2 \mathrm{MJ}$ respectively. The simulation carried out without furniture will be compared to the others based on the heater power consumption in a proceeding section.

\subsection{Case 5}

All of the analysis performed in the previous simulations do not consider the use of a heat recovery ventilation system. For better energy economy, it is wise to integrate the ventilation system with a heat recovery process. This section compensates in assessing the thermal effectiveness of the building unit with a heat recovery system with an energy efficiency of $70 \%$.

The simulation presented in the case 2 is re-assessed after combining it with the eq.(23), which is applicable in heat recovery. Table 4 points out the power consumption of the heater and ventilation heat losses in a nutshell.

An economizer with the given efficiency has increased the inflow air temperature by $14.2^{0} \mathrm{C}$. With the rise in temperature, it is found that there is a potential of saving $40 \%$ energy and minimizing ventilation heat losses by approximately $70 \%$.

\subsection{Case 6}

In the case 6 , the performance of the model is evaluated for a building unit having a larger volume than the regular one. The length and the width of the unit are twice those of the first building unit. This increases the internal volume approximately by four. With a larger volume, intensive fluctuations in the temperature profile are seen in Figure 8.

It is not possible to observe the effect of solar insolation during the day time as in case 2 and 3. According to the observations heater power consumption must be significantly higher than in the remaining cases, and this fact will be discussed under the power consumption section.

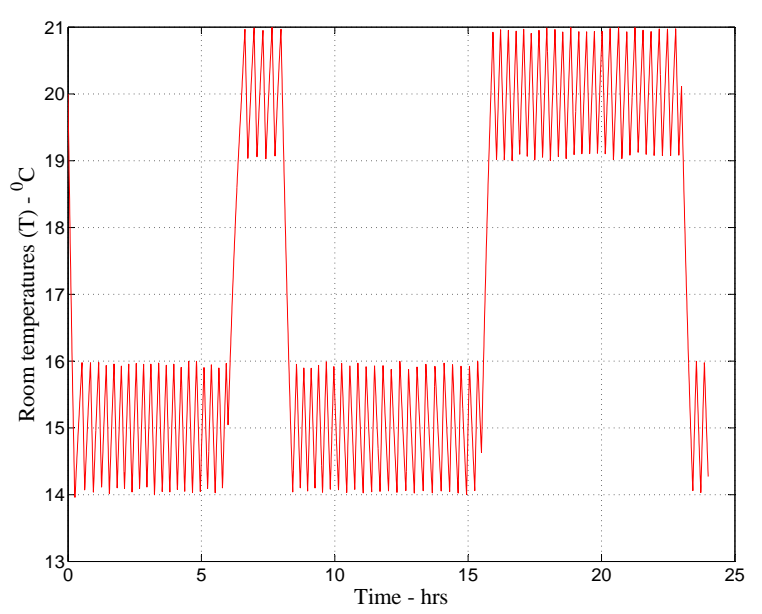

Figure 8: Temperature variations inside the large building unit

\subsection{Case 7}

As mentioned in the Introduction, the developed model for the single zone building unit can be extended to open architectural designs. As an example, a room having equivalent dimensions to the main unit is joined to the narrow side of the building unit. This new attachment (zone 2$)$ has one door $(0.75 \times 2.1 \mathrm{~m})$, and constant fresh air flow of $0.7 \mathrm{~m}^{3} /\left(\mathrm{h} . \mathrm{m}^{2}\right)$. The only heat supply to this space is from zone 1 (main building unit) via the middle wall which has an area of $3.65 \times 3.3 \mathrm{~m}$. Zone 2 is empty with no furniture. Equations from (1) to (22) represent the dynamics of each room and, in addition, the heat transfer equation over the intermediate wall is included which is given by eq.(26).

$$
\dot{Q}_{\text {centralwall }}=U_{\text {centralwall }} A_{\text {middlewall }}\left(T_{b}-T_{\text {zone } 2}\right)
$$

The attached room has the temperature variation shown in Figure 9, while the internal temperature of the main building unit is kept between the set points.

The zone 2 temperature behaves more or less similarly to the outside temperature. Heat energy transferred by conduction through the intermediate wall is not sufficient to raise the temperature of zone 2 . The introduction of a heater with a capacity of approximately $300 \mathrm{~W}$ in zone 2 can maintain the inside temperature at an average of $20^{\circ} \mathrm{C}$. 
Perera et.al., "Modelling the heat dynamics of a residential building unit"

Table 4: Assessment of Scenario 2 and Scenario 5 with respect to heat recovery ventilation

\begin{tabular}{lcc}
\hline Property & Scenario 2 & Scenario 5 \\
\hline Mean Tin & $-2.2^{0} \mathrm{C}$ & $12^{0} \mathrm{C}$ \\
Heater energy consumption & $14 \mathrm{MJ}$ & $8 \mathrm{MJ}$ \\
Ventilation heat loss & $8.7 \mathrm{MJ}$ & $2.4 \mathrm{MJ}$ \\
\hline
\end{tabular}

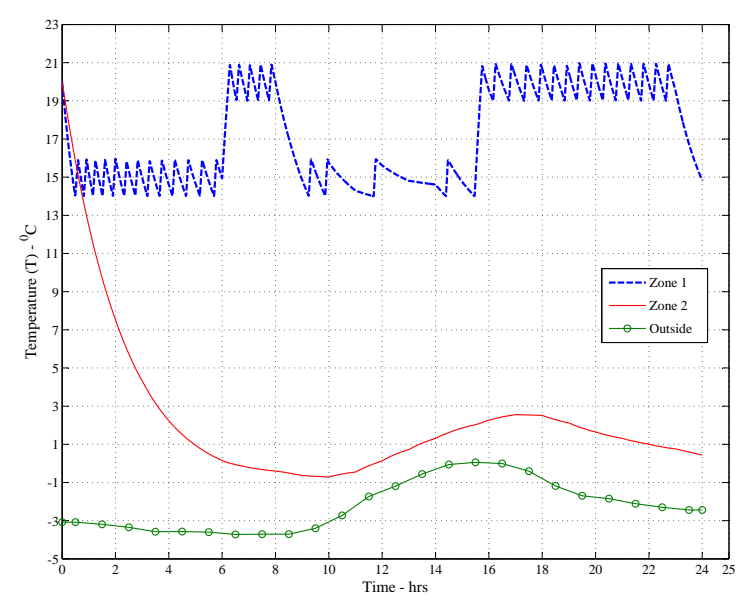

Figure 9: Temperature profiles for the two zones of the combined building

\subsection{Power consumption}

The thermic state of the building unit is influenced by the heat supply and control, ventilation, external weather conditions, building structure, the presence of furniture and occupancy. Nearly all of these determinants are assessed theoretically to see how they impact on the energy performance of a building. Figure 10 presents the estimated energy usage in space heating for the conducted simulations.

Energy consumption of cases 2, 4a, 4b, 4c and 7 vary in the same degrees. Case 4c, without furniture has little saving in energy compared to case 2 . The role of furniture as a thermal storage system, reducing the required energy for heating, may explain the logic behind this benefit. Significant reductions are observed in C3 and C5, which constitute the hermetically sealed building unit and the building unit with an integrated heat recovery system respectively. It is apparent that, without air circulation, any building structure can heat up fast with limited power demands. However, ventilation is recommended for improving indoor air quality inside the building unit. Therefore, the best alternative is to set up a heat recovery system which can battle with the energy loss associated with fresh air flows. C6 has the

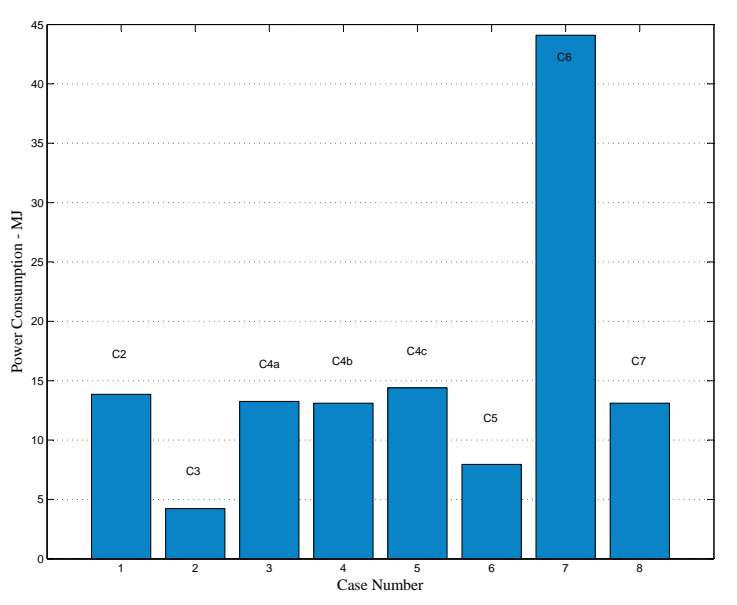

Figure 10: Power consumption of different case studies

highest energy consumption which constitutes a large building unit, and it is 3 times bigger than $\mathrm{C} 2$. A comparison of $\mathrm{C} 2$ and $\mathrm{C} 7$ shows that the energy usage of $\mathrm{C} 2$ is a little higher. The reason for this is the limited heat loss through the common wall between the two zones. The driving force of heat transfer in the direction of zone 2 through this wall is weak compared to the other walls because of the high temperature inside this region compared to outside.

\subsection{Occupancy}

Except for case 1, all the other simulated building units were incorporated with a discontinuous occupancy profile. The control of intermittently occupied heated buildings with the experience of preheating provides directions for energy conservation. Heating the building while neglecting this irregularity may cause a loss of energy. The use of an On/Off controller to maintain a nominal temperature set point of $20^{\circ} \mathrm{C}$ throughout the day cannot save a significant amount of energy. The total electrical energy consumption in the heating of such a building unit is approximately $45 \%$ higher than the one presented in case 2 . 
Table 5: Energy losses from the building block as a percentage of total loss

\begin{tabular}{cccc}
\hline Case No. & Ventilation & Wall & Other \\
\hline C2 & 28 & 40 & 32 \\
C3 & 0 & 55 & 45 \\
C4a & 28 & 40 & 32 \\
C4b & 27 & 40 & 33 \\
C4c & 27 & 40 & 33 \\
C5 & 9 & 50 & 41 \\
C6 & 32 & 11 & 57 \\
C7 & 35 & 25 & 40 \\
\hline
\end{tabular}

\subsection{Energy losses}

The main energy losses from the building unit are due to the conduction heat transfer through the framework of the building unit and convection heat transfer by ventilation. Radiation heat losses from the external surfaces to the environment are not significant owing to the presence of particularly low temperatures extrinsic to the building unit. Hence the estimations are based on overall heat transfer coefficients, which are assumed to be a combination of both convection and radiation heat transfer coefficients. Table 5 shows the substantial heat losses associated with the building unit. When calculating the total heat loss, the amount of thermal energy absorbed or released by the furniture is not taken into consideration. Other heat losses include thermal energy transfers via window, door, floor and roof.

Amongst all of the losses, wall heat losses are the highest except for the last two cases. The bigger the building unit, the higher the "ventilation" heat losses and "other" losses. Case 6 has the second highest heat losses via the roof which is $16 \%$. Losses are estimated only for zone 1 of the two zone building in case 7 . It accounts for lower wall heat losses than case 2 owing to the different heat dynamics of the intermediate wall. Significant wall heat losses can be diminished by introducing adequate insulation and ventilation heat losses can be reduced by heat recovery systems as determined by case 5 .

\section{Validation of the model using experimental data}

Data obtained from a residential building located in Norway is used to validate the developed model. Even though the building consists of two stories, the simulation is carried out only for the second floor of the building which is shown in Figure 11. The thicknesses of the walls, floor and roof, are $16 \mathrm{~cm}$ each and all are assembled with two wooden panels (each $2 \mathrm{~cm}$ ) and a mineral wool insulation $(12 \mathrm{~cm})$ in the middle. The total volume of the interested building block with the attic is $148.5 \mathrm{~m}^{3}$. There are 7 windows and 2 doors (each $1.95 \times 0.8 \mathrm{~m}^{2}$ ) found in the building block and window dimensions are given in the Figure 11. The supplied electrical heater power to heat the zone is $3250 \mathrm{~W}$ and it is regulated by an on/off controller with a set point of $7^{0} \mathrm{C}$ when the building is not occupied. This building does not consist of a mechanical ventilation system and, therefore, either mass or energy flow is not noticed. The estimated wooden furniture volume is $5 \mathrm{~m}^{3}$ including the internal building structures. The temperature of the first floor is measured approximately to have $10^{\circ} \mathrm{C}$ which will be regarded as the ground temperature in this case. The thermal process parameters presented in the Table 2 is applied to this case as well. The overall heat transfer coefficient via walls, floor and roof are $0.4 \mathrm{~W} /\left(m^{2} \mathrm{~K}\right)$.

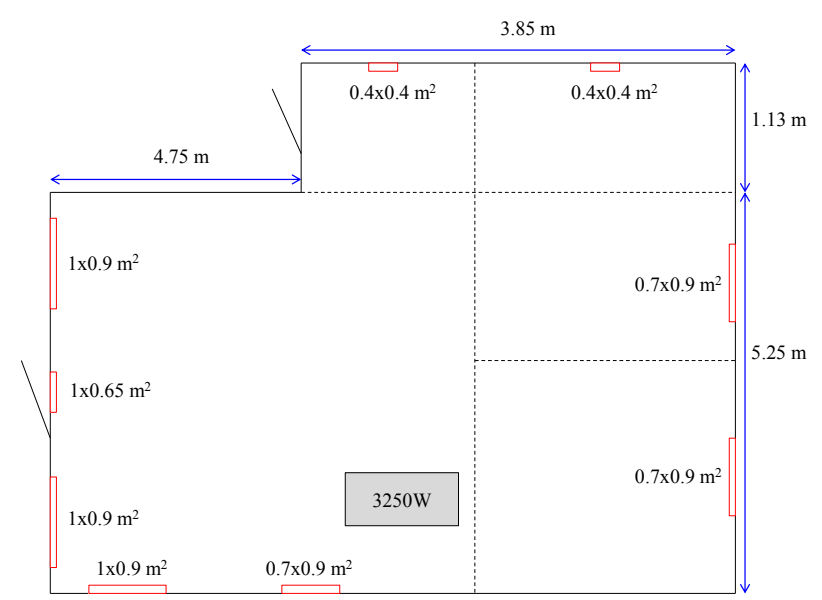

Figure 11: Structure of the simulated builing block

The data is collected for a limited period and the simulations are provided for three consecutive days 


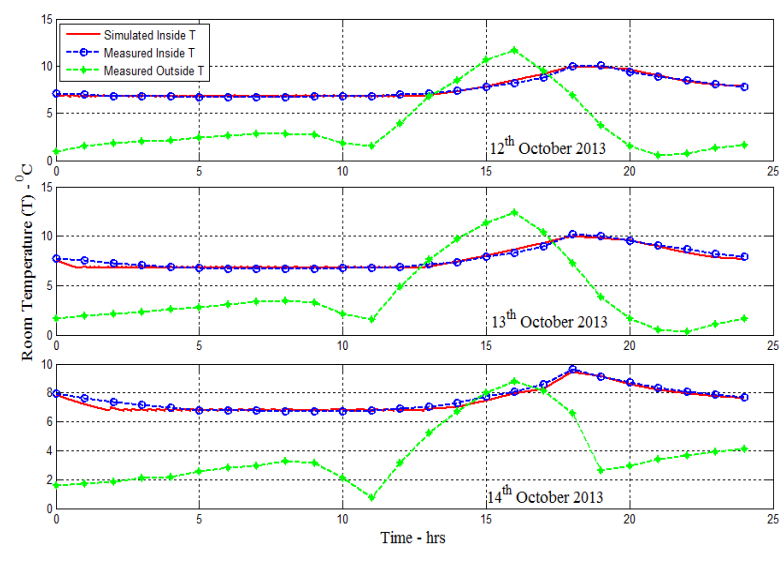

Figure 12: Inside and outside temperature variations

$\left(12^{t h}, 13^{t h}\right.$ and $14^{t h}$ October 2013). The simulated and measured inside temperatures of the building block with the measured outside temperature are presented in Figure 12. The peak inside temperature is observed around 18:00 in all the three days which was not expected at the beginning. The main reason for the temperature rise is the solar irradiation. For these three days, sunrise and sunset times were approximately at 07:50 and 18:15. In the morning, the temperature increase is slow because the building is in the shadows of trees in the east side and no effective solar irradiation. In the afternoon building envelope is heated by the direct sunlight from the west side. It could be the reason to have this peak temperature in the afternoon.

However, solar radiation was not measured in the experiment and hence not used in the simulation. Therefore, it is approximated to have an average value of $8 \mathrm{~W} /\left(m^{2} \mathrm{hr}\right), 7 \mathrm{~W} /\left(m^{2} \mathrm{hr}\right)$ and $5 \mathrm{~W} /\left(m^{2} \mathrm{hr}\right)$ for the three days respectively in the simulations. Even though, it is suspected to have some differences in the measured and simulated inside temperature curves owing to this reason, according to the Figure 12, the model predicts quite well.

\section{Conclusion}

The current work presents the modelling of heat dynamics of a residential building unit using the first principles modelling approach. The developed model has practical importance in the realm of modelling the heat dynamics of buildings because of the feasibility of extending this basic system to complex configurations.

The study elaborates different scenarios of building unit heat dynamics with regard to On/Off control, ventilation, furniture, building size, occupancy and heat recovery. Besides, heat transfer through the internal walls, the simulation of adjoining building units which confirms the ability of extending the model to diverse architectural designs is discussed. It is reasonable to conclude from the modelling results that the best thermal performance and comfortable indoor environment can be achieved when the indoor temperature is monitored and controlled accordingly; when the heater power is regulated in accordance with the usage pattern and when the ventilation system is integrated with an economizer.

It is assumed that the furniture in the building stores a fraction of the energy supplied by the electrical heater and releases it when needed depending on its thermal mass. The walls in the building account for the main energy losses depending on the size and performance of the insulation. Adequate insulation of critical building elements requires, therefore full attention.

Further work needs to be done to consolidate the approach by the comparison of more experimental and simulated data. Measurement of solar irradiation data will be imperative for reliable predictions. Model parameter estimation is significant in physical model development and attention must be given to that area as well. Moreover, the current work needs to be evaluated for complex residential buildings having several floors and several rooms on each floor. The modelling of attic roofs is also a primary requirement when it comes to Norwegian buildings.

The main goal of developing heating models for buildings is the requirement of using them for control objectives. Hence the established model should be tested for such applications.

\section{References}

Regulation requirements for building (building technical regulations) tek10. 2010.

Andersen, K. K., Madsen, H., and Hansen., L. H. Modelling the heat dynamics of a building using stochastic differential equations. Energy and Buildings, 2000. 31:13-24. doi:10.1016/S0378-7788(98)000693.

Bergesen, B., Groth, L. H., Langseth, B., Magnussen, I. H., Spilde, D., and Toutain, J. E. W. Energy consumption 2012 - household energy consumption. Technical report, Norwegian Water Resources and Energy Directorate, 2013.

Desta, T. Z., Brecht, A. V., Quanten, S., Buggenhout, S. V., Meyers, J., Baelmans, M., and Berckmans, D. Modelling and control of heat transfer phenomena 
Table 6: Nomenclature for the model.

\begin{tabular}{|c|c|c|}
\hline Symbol & Units & Description \\
\hline$A_{j}$ & $m^{2}$ & Area of $\mathrm{j}^{\text {th }}$ element \\
\hline$A_{i, j}$ & $m^{2}$ & Area of the surface between $\mathrm{i}^{\text {th }}$ and $\mathrm{i}+1^{\text {th }}$ layer of $\mathrm{j}^{\text {th }}$ element \\
\hline$c_{p, b}$ & $\frac{J}{k g \cdot K}$ & Specific heat capacity of moist air inside the building unit \\
\hline$c_{p_{i, j}}$ & $\frac{j \cdot M}{k g \cdot K}$ & Specific heat capacity of $\mathrm{i}^{\text {th }}$ layer of $\mathrm{j}^{\text {th }}$ element \\
\hline$\dot{E}_{x}$ & $\mathrm{~W}$ & Total energy flow rate to the $\mathrm{x}$ direction \\
\hline$\dot{H}_{x}$ & $\mathrm{~W}$ & Enthalpy flow rate to the $\mathrm{x}$ direction \\
\hline$h_{x}$ & $\frac{J}{k q}$ & Specific enthalpy of incoming air to the $\mathrm{x}$ direction \\
\hline$h_{b, j}$ & $\frac{\frac{N y}{W}}{m^{2} K}$ & Convection heat transfer coefficient of $\mathrm{j}^{\text {th }}$ element inside the building unit \\
\hline$h_{\infty, j}$ & $\frac{m W}{m^{2} K}$ & Convection heat transfer coefficient of $\mathrm{j}^{\text {th }}$ element outside the building unit \\
\hline$K_{i, j}$ & $\frac{m{ }_{W}^{2 k}}{m \cdot K}$ & Thermal conductivity of the $\mathrm{i}^{\text {th }}$ layer of $\mathrm{j}^{\text {th }}$ element \\
\hline$l_{i, j}$ & $\begin{array}{c}m . K \\
\mathrm{~m}\end{array}$ & Half thickness of the $\mathrm{i}^{\text {th }}$ layer of $\mathrm{j}^{\text {th }}$ element \\
\hline$M_{b}$ & $\frac{\mathrm{kg}}{\mathrm{mol}}$ & Average molar mass of moist air in the building unit \\
\hline$m_{b}$ & kg & Mass of air water mixture in the building unit \\
\hline$(P \dot{V})_{x}$ & $\mathrm{~W}$ & Pressure work to the $\mathrm{x}$ direction \\
\hline$\dot{Q}_{j}$ & $\mathrm{~W}$ & Heat gain or loss due to $\mathrm{j}^{\text {th }}$ element \\
\hline$\dot{q}_{i, j}$ & $\mathrm{~W}$ & Heat generation in the $\mathrm{i}^{\text {th }}$ layer of $\mathrm{j}^{\text {th }}$ element \\
\hline $\mathrm{R}$ & $\frac{P a \cdot m^{3}}{\text { mol.K }}$ & Gas constant \\
\hline $\mathrm{r}$ & $\mathrm{m}$ & Radius of a sphere \\
\hline$\delta r_{i, f u r}$ & $\mathrm{~m}$ & Half thickness of $\mathrm{i}^{\text {th }}$ layer in a spherical furniture \\
\hline$T_{\infty}$ & $\mathrm{K}$ & Outside temperature \\
\hline$T_{b}$ & $\mathrm{~K}$ & Temperature of air in the building unit \\
\hline$T_{\text {centre }}$ & $\mathrm{K}$ & Temperature at the centre of the assumed furniture sphere \\
\hline$T_{i, j}$ & $\mathrm{~K}$ & Temperature of the $i^{t h}$ layer of element $\mathrm{j}$ \\
\hline$T_{i, j}^{s}$ & K & Temperature of the surface between $(i-1)^{t h}$ and $i^{t h}$ layer of element $\mathrm{j}$ \\
\hline $\mathrm{t}$ & $\mathrm{s}$ & Time \\
\hline$U_{j}$ & $\frac{W}{m^{2} K}$ & Overall heat transfer coefficient of $\mathrm{j}^{\text {th }}$ element \\
\hline$\rho_{\text {in }}$ & $\frac{k g}{m^{3}}$ & Density of moist air flowing into the building unit \\
\hline$\rho_{i, j}$ & $\frac{\mathrm{kg}}{\mathrm{m}_{2}^{3}}$ & Density of $\mathrm{i}^{\text {th }}$ layer of $\mathrm{j}^{\text {th }}$ element \\
\hline$\alpha_{i, j}$ & $\frac{m^{2}}{s}$ & Thermal diffusivity of $\mathrm{i}^{\text {th }}$ layer of $\mathrm{j}^{\text {th }}$ element \\
\hline$\epsilon$ & - & Emissivity of the surface \\
\hline$\sigma$ & $\frac{W}{m^{2} K^{4}}$ & Stefan-Boltzmann constant \\
\hline
\end{tabular}


inside a ventilated air space. Energy and Buildings, 2005. 37:777-786. doi:10.1016/j.enbuild.2004.10.006.

Frostrup, A. Tomrerteori Konstruksjoner $i$ tre. Universitets Forlaget, 1999.

Gendelis, S. and Jakovics, A. Numerical modelling of airflow and temperature distribution in a living room with different heat exchange conditions. Latvian journal of physics and technical sciences, 2010. 4:27-43. doi:10.2478/v10047-010-0016-z.

Harley, B. Insulate and weatherize your home : expert advice from start to finish. Taunton Press, 2002.

Havenith, G., Holmer, I., and Parsons, K. Personal factors in thermal comfort assessment: clothing properties and metabolic heat production. Energy and Buildings, 2002. 34:581-591. doi:10.1016/S03787788(02)00008-7.

Kazanavicius, E., Mikuckas, A., Mikuckiene, I., and Ceponis, J. The heat balance model of residential house. Information technology and control, 2006. 35:391-396.
Lee, Y. M., Fei, L., Lianjun, A., Huijing, J., Reddy, C., Horesh, R., Nevill, P., Meliksetian, E., Chowdhary, P., Mills, N., Tae, C. Y., Snowdon, J., Kalagnanam, J., Emberson, J., Paskevicous, A., Jeyaseelan, E., Forest, R., Cuthbert, C., Cupido, T., Bobker, M., and Belfast, J. Modeling and simulation of building energy performance for portfolios of public buildings. In Simulation Conference (WSC), Proceedings of the 2011 Winter. 2011. doi:10.1109/WSC.2011.6147817.

Mendes, N., Oliveira, G. H. C., Arajo, H. X., and Coelho, L. S. A matlab based simulation tool for building thermal performance analysis. Building Simulation, 2003. pages 855-862.

Olseth, J. A. and Skartveit, A. The solar radiation climate of norway. Solar Energy, 1986. 37:423-428. doi:10.1016/0038-092X(86)90033-2.

Wang, L. and Wong, N. H. Coupled simulations for naturally ventilated rooms between building simulation (bs) and computational fluid dynamics (cfd) for better prediction of indoor thermal environment. Building and Environment, 2009. 44:95-112. doi:10.1016/j.buildenv.2008.01.015. 